\title{
Effect of temperature and porosities on dynamic response of functionally graded beams carrying a moving load
}

\author{
Bui Van Tuyen
}

\begin{abstract}
The effect of temperature and porosities on the dynamic response of functionally graded beams carrying a moving load is investigated. Uniform and nonlinear temperature distributions in the beam thickness are considered. The material properties are assumed to be temperature dependent and they are graded in the thickness direction by a power-law distribution. A modified rule of mixture, taking the porosities into consideration, is adopted to evaluate the effective material properties. Based on Euler-Bernoulli beam theory, equations of motion are derived and they are solved by a finite element formulation in combination with the Newmark method. Numerical results show that the dynamic amplification factor increases by the increase of the temperature rise and the porosity volume fraction. The increase of the dynamic amplification factor by the temperature rise is more significant by the uniform temperature rise and for the beam associated with a higher grading index.
\end{abstract}

Index Terms-Functionally graded material, porosities, temperature-dependent properties, dynamic response, moving load, Euler-Bernoulli beam.

\section{INTRODUCTION}

$A$ nalyses of structures made of functionally A graded materials (FGMs) have been extensively carried out since the materials were created by Japanese scientist in mid-1980s. The smooth variation of the effective material properties enables these materials to overcome the

Manuscript Received on July 13 ${ }^{\text {th }}$, 2016. Manuscript Revised December $06^{\text {th }}, 2016$.

This research is funded by Vietnam National Foundation for Science and Technology Development (NAFOSTED) under grant number 107.02-2015.02.

Bui Van Tuyen is a lecturer at Thuy Loi University, 175 Tay Son, Dong Da, Hanoi, Vietnam (e-mail: tuyenbv@tlu.edu.vn). drawbacks of the conventional composite materials. Many investigations on the behaviour of FGM structures subjected to thermal and mechanical loadings are available in the literature, contributions that are most relevant to the present work are briefly discussed below.

Chakraborty et al. [1] employed the exact solution of homogeneous governing equations of a FGM Timoshenko beam segment to develop a beam element for vibration analysis of FGM beams. The third-order shear deformation theory was used in formulation of a finite beam element for studying the static behaviour of FGM beams [2]. Li [3] presented a unified approach for investigating the static and dynamic behaviour of FGM beams. The finite element method was used to study the free vibration and stability of beams made of transversely or axially FGM [4],[5]. Nonlinear beam elements were derived for the large displacement analysis of tapered FGM beams subjected to end forces [6], [7], [8]. Meradjah et al [9] proposed a new higher order shear and normal deformation theory for bending and vibration analysis of FGM beams. Sallai et al [10] presented an analytical solution for bending analysis of a FGM beam. A new refined hyperbolic shear and normal deformation beam theory was proposed for studying the free vibration and buckling of FGM sandwich beams [11]. Vibration analysis of FGM beams under moving loads, the topic of this paper, has been considered by several authors recently. In this line of work, Şimşek và Kocatürk [12] used polynomials to approximate the displacements in derivation of discretized equations for a FGM Euler-Bernoulli beam under a moving harmonic load. Lagrange multiplier method was then employed in combination with Newmark method to compute the vibration characteristics of the beams. The method was then employed to study the vibration of FGM beams under a moving mass and a nonlinear FGM Timoshenko beam subjected to a 
moving harmonic load [13], [14]. Khalili et al [15] used the mix Rizt-differential quadrature method to compute the dynamic response of FGM EulerBernoulli beams carrying moving loads. The Runge-Kutta method was employed to investigate the dynamic behavior of a FGM Euler-Bernoulli beam under a moving oscillator [16]. Nguyen et al [17], Gan et al [18] employed the finite element method to study the dynamic behaviour of FGM beams traversed by moving forces.

FGMs were employed for the development of structural components under severe thermal loadings. Investigation on the behaviour of FGM structures in thermal environment is an important topic, and it has drawn much attention from researchers. Kim [19] employed Rayleigh-Ritz method to study the free vibration of a third-order shear deformable FGM plate in thermal environment. Pradhan and Murmu [20] used the modified differential quadrature method to solve equations of motion of the free vibration of FGM sandwich beams resting on variable foundations. Based on the higher-order shear deformation theory, Mahi et al [21] derived an analytical solution for free vibration of FGM beams with temperature-dependent material properties. The improved third-order shear deformation theory was used to study the thermal buckling and free vibration of FGM beams [22]. The authors concluded that the fundamental frequency approaches to zero when the temperature rises towards the critical temperature. The effect of porosities which can be occurred inside FGMs during the process of sintering on the behaviour of FGM beams has been considered in recent years. Wattanasakulpong and Chaikittiratana [23] took the effect of porosities into account by using a modified rule of mixture to evaluate the effective material properties in the free vibration of FGM beams. Atmane et al [24] proposed a computational shear displacement model for free vibrational analysis of FGM porous beams. The Ritz method was used to obtain expressions of the critical load and bending deflection of Timoshenko beams composed of porous FGM [25]. Ebrahimi et al [26] used the differential quadrature method to study the free vibration of FGM porous beams in thermal environment. It has been shown by the authors that the fundamental frequency of the beams is significantly influenced by both the temperature and porosities.

To the authors' best knowledge, the effect of temperature and porosities on the dynamic response of FGM beams has not been reported in the literature and it will be investigated in the present work. The material properties of the beams are considered to be temperature - dependent and they are graded in the thickness direction by a powerlaw distribution. Two type of temperature distribution, namely uniform and nonlinear temperature rises obtained as solution of the heat transfer Fourier equation are considered. A modified rule of mixture is adopted to evaluate the effective material properties. Equations of motion based on Euler - Bernoulli beam theory are derived from Hamilton's principle and they are solved by a finite element formulation in combination with the Newmark method. A parametric study is carried out to highlight the effect of the temperature rise the the porosity volume fraction of the dynamic response of the beam.

\section{FUNCTIONALLY GRADED BEAM}

A simply supported FGM beam carrying a load $\mathrm{P}$, moving along the $\mathrm{X}$-axis as depicted in Fig. 1 is considered. In the figure, the Cartesian co-ordinate system $(\mathrm{x}, \mathrm{z})$ is chosen as that the $\mathrm{x}$-axis is on the mid-plane, and the z-axis is perpendicular to the mid-plane. Denoting $\mathrm{L}, \mathrm{h}$ and $\mathrm{b}$ as the length, height and width of the beam, respectively. The present study is carried out based on the following assumptions: (i) The load P is always in contact with the beam and its moving speed is constant; (ii) the inertial effect of the moving load is negligible; (iii) the beam is initially at rest, that means the initial conditions are zero.

The beam is assumed to be composed of metal and ceramic whose volume fraction varies in the $\mathrm{z}$ direction as

$$
V_{c}=\left(\frac{z}{h}+\frac{1}{2}\right)^{n}, V_{c}+V_{m}=1
$$

where $V_{c}$ and $V_{m}$ are respectively the volume fractions of ceramic and metal, and $\mathrm{n}$ is the nonnegative grading index, which dictates the variation of the constituent materials. As seen from Eqs.1, the bottom surface corresponding to $\mathrm{z}=-\mathrm{h} / 2$ contains only metal, and the top surface corresponding to $\mathrm{z}=\mathrm{h} / 2$ is pure ceramic. 


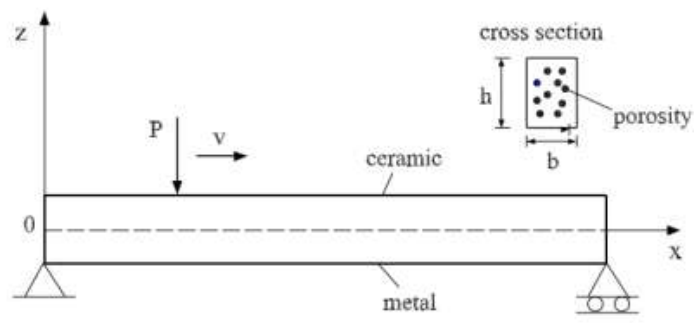

Figure 1. A simply supported FGM porous beam carrying a moving load

The beam is considered to be in thermal environment, and its material properties are assumed to be temperature - dependent. A typical material property $(\mathrm{P})$ is a function of environment temperature $(\mathrm{T})$ as $[27]$

$$
P=P_{0}\left(P_{-1} T^{-1}+1+P_{1} T+P_{2} T^{2}+P_{3} T^{3}\right)
$$

where $T=T_{0}+\Delta T$, with $T_{0}=300 \mathrm{~K}$ is reference temperature and $\Delta T$ is the temperature rise, is the current environment temperature; $P_{1}, P_{0}, P_{1}, P_{2}, P_{3}$ are the coefficients of temperature $T(\mathrm{~K})$, and they are unique to the constituent materials [26].

In order to take the effect of porosities into consideration, the modified rule of mixture [23] is adopted herewith

$$
P=P_{c}\left(V_{c}-\frac{1}{2} V_{\alpha}\right)+P_{c}\left(V_{m}-\frac{1}{2} V_{\alpha}\right)
$$

where $P_{m}$ and $P_{c}$ are respectively the properties of metal and ceramic, and $V_{\alpha}(<<1)$ is the porosity volume fraction. From (1) and (3), the effective Young's modulus $(E)$, the thermal expansion coefficient $(\alpha)$ and the mass density $(\rho)$ of the FGM porous beam are given by

$$
\begin{aligned}
E(z, T) & =\left[E_{c}(T)-E_{m}(T)\right]\left(\frac{z}{h}+\frac{1}{2}\right)^{n} \\
& +E_{m}(T)-\frac{V_{\alpha}}{2}\left[E_{c}(T)+E_{m}(T)\right] \\
\alpha(z, T)= & {\left[\alpha_{c}(T)-\alpha_{m}(T)\right]\left(\frac{z}{h}+\frac{1}{2}\right)^{n} } \\
& +\alpha_{m}(T)-\frac{V_{\alpha}}{2}\left[\alpha_{c}(T)+\alpha_{m}(T)\right] \\
\rho(z)= & \left(\rho_{c}-\rho_{m}\right)\left(\frac{z}{h}+\frac{1}{2}\right)^{n}+\rho_{m}-\frac{V_{\alpha}}{2}\left(\rho_{c}+\rho_{m}\right)
\end{aligned}
$$

where the mass density is considered to be temperature-independent.

Temperature variation is considered to occur in the thickness direction only, and it is assumed that the temperature is imposed to prescribed values on the top and bottom surface, $T=T_{c}$ at $z=h / 2$, and $T$ $=\operatorname{Tm}$ at $z=h / 2$. In this case, the temperature distribution can be obtained by solving the following steady - state heat transfer Fourier equation [19].

$$
-\frac{d}{d z}\left[\kappa(z) \frac{d T}{d z}\right]=0
$$

where $\kappa$ is the thermal conductivity, assumed to be independent to the temperature. The solution of (5) is as follows

$$
T=T_{m}+\left(T_{c}-T_{m}\right) \frac{\int_{-h / 2}^{z} \frac{1}{\kappa(z)} d z}{\int_{-\frac{h}{2}}^{\frac{h}{2}} \frac{1}{\kappa(z)} d z}
$$

If $T_{c}=T_{m}$, (6) gives a uniform temperature rise (UTR), otherwise it leads to a nonlinear temperature rise (NLTR). The temperature distribution in the thickness direction for the NLTR with a temperature rise $\Delta T=300 \mathrm{~K}$ is depicted in Fig. 2 for various values of the index $n$.

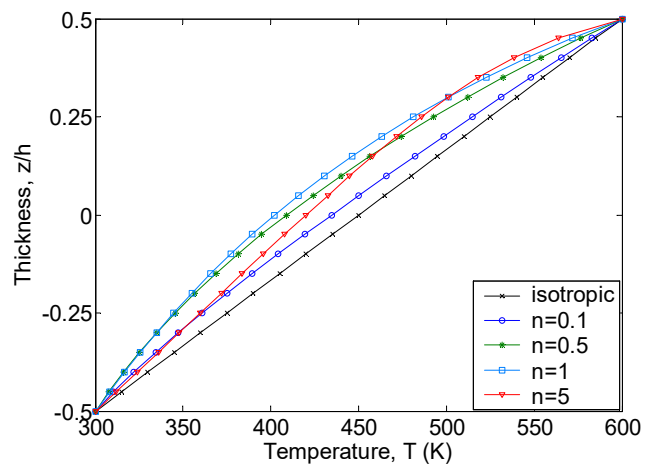

Figure 2. Temperature distribution in thickness direction for NLTR.

Based on the temperature distribution in (6), the temperature-dependent material properties are evaluated by using (4). Fig. 3 illustrates the variation of the Young's modulus in the beam thickness for the two cases of temperature rises and for different indexes $n$ and $V_{\alpha}=0.1$. As seen from the figure, the effective Young's modulus decreases more significantly by the UTR than it does by the NLTR. Noting that Figs. 2 and 3 have been plotted for a FGM beam formed from Alumina and Steel. The material data of Alumina and Steel are given in Ref. [26]. 


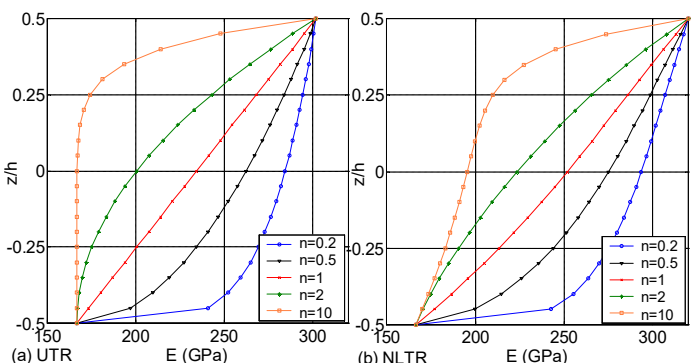

Figure 3. Variation of Young's modulus in thickness direction for a temperature rise $\Delta T=300 \mathrm{~K}$ and a porosity volume fraction $V_{\alpha}=0.1$

\section{GOVERNING EQUATION}

Based on the Euler-Bernoulli beam theory, the displacements $u$ and $w$ of an arbitrary point in the $x$ and $z$ directions, respectively are given by.

$$
\begin{aligned}
& u(x, z, t)=u_{0}(x, t)-z w_{0, x} \\
& \mathrm{w}(x, z, t)=w_{0}(x, t)
\end{aligned}
$$

where $u_{0}(x, t)$ and $w_{0}(x, t)$ are respectively the axial and transverse displacements of a point on the $x$-axis; $t$ is the time, and (..), $x$ denotes the derivative with respect to $x$. Based on linearly elastic behaviour, the normal strain $(\varepsilon)$ and normal stress $(\sigma)$ are as follows

$$
\varepsilon=u_{0, x}-z w_{0, x x}, \sigma(z, T)=E(z, T)\left(u_{o, x}-z w_{o, x x}\right)
$$

The strain energy for the beam $\left(U_{B}\right)$ resulted from the mechanical loads reads

$$
\begin{aligned}
U_{B} & =\frac{1}{2} \int_{0}^{L} \int_{A} \sigma \varepsilon d A d x \\
& =\frac{1}{2} \int_{0}^{L}\left(A_{11} u_{0, x}^{2}-2 A_{12} u_{0, x} w_{0, x x}+A_{22} w_{0, x x}^{2}\right) d x
\end{aligned}
$$

where $A_{11}, A_{12}$ and $A_{22}$ are respectively the extensional, extensional-bending coupling and bending rigidities, defined as

$$
\left(A_{11}, A_{12}, A_{22}\right)=\int_{A} E(z, T)\left(1, z, z^{2}\right) d A
$$

with $\mathrm{A}$ is the cross-sectional area. With the effective Young's modulus and temperature given by (4) and (6), the above rigidities can be easily evaluated.

The strain energy from initial stress due to the temperature rise $\left(U_{T}\right)$ is given by [21].

$U_{T}=\frac{1}{2} \int_{0}^{L} N_{T} w_{0, x}^{2} d x$

where $N_{T}$ is the axial force resultant caused by elevated temperature, defined as

$$
N_{T}=-\int_{A} E(z, T) \alpha(z, T) \Delta T d A
$$

with $\Delta T$, as mentioned above, is the temperature rise. The kinetic energy of the beam ( $\mathrm{T}$ ) resulted from Eq. (7) is

$$
\begin{aligned}
\mathrm{T} & =\frac{1}{2} \int_{V} \rho(z)\left(\dot{u}^{2}+\dot{w}^{2}\right) d V \\
& =\frac{1}{2} \int_{0}^{L}\left[I_{11}\left(\dot{u}_{0}^{2}+\dot{w}_{0}^{2}\right)-2 I_{12} \dot{u}_{0} \dot{w}_{0, x}+I_{22} \dot{w}_{0, x}^{2}\right] d x
\end{aligned}
$$

where an overdot denotes the differentiation with respect to time, and $I_{11}, I_{12}, I_{22}$ are the mass moments defined as

$$
\left(I_{11}, I_{12}, I_{22}\right)=\int_{A} \rho(z)\left(1, z, z^{2}\right) d A
$$

with $\rho(z)$ is temperature. Finally, the potential of the moving forces $(V)$ has a simply form as

$$
\mathrm{V}=-\sum_{i=1}^{N} P w_{0}(x, t) \delta(x-v t)
$$

with $\delta($.$) is the delta Dirac function; x$ is the current position of load $P$ with respect to the left end of the beam.

Applying Hamilton's principle to (9), (11), (13) and (15), we obtain the following equations of motion for the beam

$$
\left\{\begin{array}{l}
I_{11} \ddot{u}_{0}-I_{12} \ddot{w}_{0, x}-A_{11} u_{0, x x}+A_{12} w_{0, x x x}=0 \\
I_{11} \ddot{w}_{0}-I_{12} \ddot{u}_{0, x}+I_{22} \ddot{w}_{0, x x}-A_{22} w_{0, x x x x} \\
\quad+A_{12} u_{0, x x x}-N_{T} w_{0, x x}=-P \delta(x-v t)
\end{array}\right.
$$

The natural boundary conditions for the beam are as follows

$$
\begin{gathered}
A_{11} u_{0, x}-A_{12} w_{0, x x}=\bar{N} \text { at } x=0 \text { and } x=L \\
\quad \text { or } u_{0}(0, t)=0 \\
-A_{12} u_{0, x x}+A_{22} w_{0, x x x x}=\bar{Q} \text { at } x=0 \text { and } x=L(17) \\
\text { or } w_{0}(0, t)=w_{0}(L, t)=0 \\
A_{12} u_{0, x}-A_{22} w_{0, x x}=\bar{M} \text { at } x=0 \text { and } x=L
\end{gathered}
$$

where are $\bar{N}, \bar{Q}$ and $\bar{M}$ respectively the prescribed axial, shear forces and moments at the beam ends.

The finite element method is employed herewith to solve the system of (16). To this end, the beam is assumed to be divided into a number of two-node elements with length of $l$. The vector of nodal displacements (d) for an element has six components as

$$
\mathbf{d}=\{\mathbf{u} \mathbf{w}\}^{T}
$$


where $\mathbf{u}=\left\{\begin{array}{ll}u_{1} & u_{2}\end{array}\right\}$ and $\mathbf{w}=\left\{\begin{array}{llll}w_{1} & \theta_{1} & w_{2} & \theta_{2}\end{array}\right\}$ are respectively the vectors of nodal axial and bending degrees of freedom at note 1 and node 2. In (18) and hereafter the superscript ' $T$ ' is used to denote a transpose of a vector or a matrix. The order of nodal degrees of freedom is not necessary as in (18), but it is convenient to separate the axial and bending degrees of freedom.

The axial displacement $u_{0}$ and the transverse displacement $w_{0}$ are interpolated from the nodal displacements according to

$$
u_{0}=\mathbf{H}_{u} \mathbf{u}, w_{0}=\mathbf{H}_{w} \mathbf{w}
$$

where $\mathbf{H}_{u}=\left\{H_{u 1} H_{u 2}\right\}, \mathbf{H}_{w}=\left\{H_{w 1} H_{\theta 1} H_{w 2} H_{\theta 2}\right\}$ are the matrices of shape functions. The following linear and cubic polynomials are used as the shape functions

$$
H_{u 1}=\frac{l-x}{l} ; H_{u 2}=\frac{x}{l}
$$

and

$$
\begin{aligned}
& H_{w 1}=1-3 \frac{x^{2}}{l^{2}}+2 \frac{x^{3}}{l^{3}}, H_{w 2}=x-2 \frac{x^{2}}{l}+\frac{x^{3}}{l^{2}} \\
& H_{w 3}=3 \frac{x^{2}}{l^{2}}-2 \frac{x^{3}}{l^{3}}, H_{w 4}=-\frac{x^{2}}{l}+\frac{x^{3}}{l^{2}} .
\end{aligned}
$$

Using the above shape functions, one can write the strain energy $U_{B}$ in the form

$$
U_{B}=\frac{1}{2} \sum_{i=1}^{n e} \mathbf{d}_{i}^{T} \mathbf{k}_{i} \mathbf{d}_{i}
$$

where ne is the total number of elements, and $\mathbf{k}$ is the element stiffness matrix, which can be written in form of sub-matrices as

$$
\mathbf{k}=\left[\begin{array}{cc}
\mathbf{k}_{a a} & \mathbf{k}_{a b} \\
\mathbf{k}_{a b}^{T} & \mathbf{k}_{b b}
\end{array}\right]
$$

in which $\mathbf{k}_{\mathrm{aa}}, \mathbf{k}_{\mathrm{ab}}$ and $\mathbf{k}_{\mathrm{bb}}$ are respectively the stiffness matrices resulted from the extensional, extensional - bending coupling and bending with the following forms

$$
\begin{aligned}
& \mathbf{k}_{a a}=\frac{A_{11}}{l}\left[\begin{array}{cc}
1 & -1 \\
-1 & 1
\end{array}\right], \mathbf{k}_{a b}=-\frac{A_{12}}{l}\left[\begin{array}{cccc}
0 & 1 & 0 & -1 \\
0 & -1 & 0 & 1
\end{array}\right] \\
& \mathbf{k}_{b b}=\frac{A_{22}}{l^{3}}\left[\begin{array}{cccc}
12 & 6 l & -12 & 6 l \\
6 l & 4 l^{2} & -6 l & 2 l^{2} \\
-12 & -6 l & 12 & -6 l \\
6 l & 2 l^{2} & -6 l & 4 l^{2}
\end{array}\right]
\end{aligned}
$$

The strain energy resulted from the temperature rise can be written as

$$
U_{T}=\frac{1}{2} \sum_{i=1}^{n e} \mathbf{d}_{i}^{T} \mathbf{k}_{T i} \mathbf{d}_{i}
$$

where the element stiffness matrix $\mathbf{k}_{T}$ has the form

$$
\mathbf{k}_{T}=\frac{N_{T}}{30 l}\left[\begin{array}{cccc}
36 & 3 l & -36 & 3 l \\
3 l & 4 l^{2} & -3 l & -l^{2} \\
-36 & -3 l & 36 & -3 l \\
3 l & -l^{2} & -3 l & 4 l^{2}
\end{array}\right]
$$

Zero entries corresponding the axial degrees of freedom should be added to $\mathbf{k}_{T}$ to form a matrix with the same size as $(6 \times 6)$ element stiffness matrix.

Similarly, the kinetic energy can be written as

$$
\mathrm{T}_{e}=\frac{1}{2} \sum_{i=1}^{n e} \dot{\mathbf{d}}_{i}^{T} \mathbf{m}_{i} \dot{\mathbf{d}}_{i}
$$

where $\mathbf{m}$ is the element consistent mass matrix, which can be written in sub-matrices as

$$
\mathbf{m}=\left[\begin{array}{cc}
\mathbf{m}_{u u} & \mathbf{m}_{\mathrm{uw}} \\
\mathbf{m}_{u \mathrm{w}}^{T} & \mathbf{m}_{\mathrm{w} \theta}
\end{array}\right]
$$

in which

$$
\begin{aligned}
& \mathbf{m}_{u u}=\frac{l}{6} I_{11}\left[\begin{array}{ll}
2 & 1 \\
1 & 2
\end{array}\right], \\
& \mathbf{m}_{\mathrm{uw}}=\frac{1}{12} I_{12}\left[\begin{array}{cccc}
6 & -l & -6 & l \\
6 & l & -6 & -l
\end{array}\right]
\end{aligned}
$$

$$
\begin{aligned}
\mathbf{m}_{\mathrm{w} \theta}= & \frac{l}{420} I_{11}\left[\begin{array}{cccc}
156 & 22 l & 54 & -13 l \\
22 l & 4 l^{2} & 13 l & -3 l^{2} \\
54 & 13 l & 156 & -22 l \\
-13 l & -3 l^{2} & -22 l & 4 l^{2}
\end{array}\right] \\
& +\frac{I_{22}}{30 l}\left[\begin{array}{cccc}
12 & 6 l & -12 & 6 l \\
6 l & 4 l^{2} & -6 l & 2 l^{2} \\
-12 & -6 l & 12 & -6 l \\
6 l & 2 l^{2} & -6 l & 4 l^{2}
\end{array}\right]
\end{aligned}
$$

Having the element stiffness and mass matrices derived, the finite element equation for dynamic analysis of the beam ignoring the damping effect can be written in the form

$$
\mathbf{M D}+\mathbf{K D}=\mathbf{F}_{\mathrm{ex}}
$$


where $\mathbf{D}, \mathbf{M}, \mathbf{K}$ are the structural nodal displacement vector, mass and stiffness matrices, respectively; $\mathbf{F}_{\text {ex }}$ is the structural nodal load vector with the following form

$$
\mathbf{F}_{\mathbf{e x}}=\{0 \ldots 0 \ldots \underbrace{\left.00 P \mathbf{N}_{w}\right|_{x e}}_{\text {loadingelement }} \ldots 0 \ldots \ldots 0\}^{T}
$$

The above nodal load vector contains all zero coefficients, except for the element currently under loading. The notation $\left.\mathbf{N}_{w}\right|_{x e}$ in (31) means that the shape functions $\mathbf{N}_{w}$ are evaluated at the abscissa $x e$, the current position of the load $P$ with respect to the element left node.

The system of equations (30) can be solved by the direct integration Newmark method. The average acceleration method described by [28], ensuring the unconditional convergence is adopted herein. In the free vibration analysis, the right hand side of (30) is set to zeros, and a harmonic response is assumed, so that (30) deduces to an eigenvalue problem, which can be obtained by the standard method.

\section{Numerical RESUlts AND Discussion}

The effect of temperature rise and volume fraction of porosities on the dynamic response of a simply supported FGM beam carrying a moving load is numerically investigated in this Section. The beam material is assumed to be composed of Alumina and Steel with the properties of constituent materials are given in Ref. [26]. The following dimensionless parameters are introduced

$$
t^{*}=\frac{t}{T_{\text {tot. }}}, w^{*}=\frac{w_{0}(L / 2, t)}{w_{\text {st. }}}, \mathrm{DAF}=\max \left[\frac{w_{0}(L / 2, t)}{w_{\text {st. }}}\right]
$$

where $T_{\text {tot. }}$ is total time necessary for one load to cross the beam, and $w_{\text {st. }}=P L^{3} / 48 E_{\text {steel }} I$ is the maximum static load of a full steel beam under a load $P$. The parameter DAF in (32) is defined in the same way as the dynamic amplification factor of an isotropic beam under a moving load and it is also called the dynamic amplification factor herein. An aspect ratio $L / h=20$ and 500 steps for the Newmark method are employed in all the computations reported below.
TABLE 1

COMPARISON OF FREQUENCY PARAMETER OF FGM POROUS

\begin{tabular}{|c|c|c|c|c|c|c|c|}
\hline$V_{\alpha}$ & $\Delta T \mathrm{~K}$ & $\begin{array}{l}\text { Temper- } \\
\text { ature }\end{array}$ & source & $n=0.1$ & $n=0.2$ & $n=0.5$ & $n=1$ \\
\hline \multirow{8}{*}{0.1} & \multirow{5}{*}{20} & \multirow[t]{2}{*}{ UTR } & Present & 4.7969 & 4.4913 & 3.9395 & 3.5202 \\
\hline & & & Ref. [26] & 4.8339 & 4.5215 & 3.9598 & 3.5347 \\
\hline & & \multirow[t]{2}{*}{ NLTR } & Present & 4.8458 & 4.5432 & 3.9950 & 3.5769 \\
\hline & & & Ref. [26] & 4.8766 & 4.5627 & 3.9914 & 3.5545 \\
\hline & & \multirow[t]{2}{*}{ UTR } & Present & 4.6106 & 4.2997 & 3.7389 & 3.3140 \\
\hline & \multirow{3}{*}{40} & & Ref. [26] & 4.6575 & 4.3385 & 3.7658 & 3.3336 \\
\hline & & \multirow[t]{2}{*}{ NLTR } & Present & 4.7582 & 4.4553 & 3.9058 & 3.4855 \\
\hline & & & Ref. [26] & 4.7889 & 4.4694 & 3.8814 & 3.4280 \\
\hline \multirow{8}{*}{0.2} & \multirow{5}{*}{20} & \multirow[t]{2}{*}{ UTR } & Present & 5.0289 & 4.6601 & 4.0119 & 3.5332 \\
\hline & & & Ref. [26] & 5.0693 & 4.6925 & 4.0328 & 3.5472 \\
\hline & & \multirow[t]{2}{*}{ NLTR } & Present & 5.0723 & 4.7063 & 4.0617 & 3.5836 \\
\hline & & & Ref. [26] & 5.1064 & 4.7282 & 4.0574 & 3.5558 \\
\hline & & \multirow[t]{2}{*}{ UTR } & Present & 4.8670 & 4.4930 & 3.8362 & 3.3521 \\
\hline & \multirow{3}{*}{40} & & Ref. [26] & 4.9182 & 4.5346 & 3.8640 & 3.3715 \\
\hline & & \multirow[t]{2}{*}{ NLTR } & Present & 4.9964 & 4.6302 & 3.9840 & 3.5037 \\
\hline & & & Ref. [26] & 5.0308 & 4.6471 & 3.9580 & 3.4354 \\
\hline
\end{tabular}
BEAM IN THERMAL ENVIRONMENT

TABLE 2

COMPARISON OF MAXIMUM DAF AND CORRESPONDING MOVING LOAD SPEED OF FGM BEAM WITHOUT TEMPERATURE AND POROSITY EFFECT

\begin{tabular}{ccccc}
\hline \hline & \multicolumn{2}{c}{ Present work } & \multicolumn{2}{c}{$[12]$} \\
$n$ & $\max (\mathrm{DAF})$ & $\begin{array}{c}v \\
(\mathrm{~m} / \mathrm{s})\end{array}$ & $\max (\mathrm{DAF})$ & $v(\mathrm{~m} / \mathrm{s})$ \\
\hline 0.2 & 1.0347 & 222 & 1.0344 & 222 \\
0.5 & 1.1445 & 197 & 1.1444 & 198 \\
1 & 1.2504 & 179 & 1.2503 & 179 \\
2 & 1.3377 & 164 & 1.3376 & 164 \\
$\mathrm{SUS304}$ & 1.7326 & 132 & 1.7324 & 132 \\
$\mathrm{~A} 2 \mathrm{O} 3$ & 0.9329 & 252 & 0.9328 & 252 \\
\hline \hline
\end{tabular}

The derived formulation is firstly validated by comparing the numerical results obtained in the present paper with the available data. In Table 1, the frequency parameter $\bar{\omega}=\omega L^{2} / h \sqrt{\rho_{m} / E_{m}}$ of FGM porous beam in thermal environment the present work is compared to that of Ebrahimi et al. (2015), obtained by using the differential transform method. The comparison of the maximum amplification factor and the corresponding moving speed is given Table 2. The numerical result in Table 2 has been obtained by using the geometric 
and material data given in the paper by Şimşek, and Kocatürk (2009) and by steadily raising the moving speed with an increment of $1 \mathrm{~m} / \mathrm{s}$, as suggested in the paper. As seen from the Tables, the frequency parameter and the dynamic response obtained in the present work are in good agreement with that of Ebrahimi et al [26] and Şimşek, and Kocatürk [12], respectively. It should be noted that the frequency and dynamic amplification factor given in Tables 1 and 2 were converged by using sixteen elements, and this number of elements is used in the below computations.

Table 3 lists the DAF of the beam with various values of the temperature rise and the grading index $n$ for a porosity volume fraction $V_{\alpha}=0.1$. It can be observable from the Table that the effect of the grading index $n$ on the DAF of the FGM porous beam in thermal environment is similar to that of the FGM without the temperature and porosity effect. At a given value of the temperature rise and of the moving speed, the DAF is increased by the increase of the index $n$. The effect of temperature rise on the DAF of the beam is clearly seen from the Table. The DAF steadily increases by the increase of the temperature rise, regardless of the index $n$ and the type of temperature distribution. By examining Table 3 in more detail, one can see that the DAF of the beam associated with a higher index $n$ is much more sensitive to the temperature change, irrespective of the moving speed. For example, an increase of $82.49 \%$ in the DAF when raising $T$ from $20 \mathrm{~K}$ to $80 \mathrm{~K}$ for the beam carrying a load with $v=20 \mathrm{~m} / \mathrm{s}$ in UTR is seen for $n=10$, while this value is just $34.66 \%$ and $55.47 \%$ for $n=0.2$ and $n$ $=1$, respectively. The reason of this is that the beam with a higher index $n$ contains more metal, and comparing to ceramic, Young's modulus of metal decreases more significantly by the temperature rise. Table 4 also shows that the increase of the DAF by the NLTR is less pronounced than by the UTR, regardless of the index $n$.

TABLE 3

DAF FOR VARIOUS VALUES OF TEMPERATURE RISE AND GRADING INDEX $n(\mathrm{~V} \alpha=0.1)$

\begin{tabular}{|c|c|c|c|c|c|c|}
\hline $\begin{array}{l}\text { Tempe } \\
\text { rature }\end{array}$ & $\begin{array}{c}v \\
(\mathrm{~m} / \mathrm{s} \\
)\end{array}$ & $\begin{array}{c}\Delta \mathrm{T}( \\
\mathrm{K})\end{array}$ & $n=0.2$ & $n=0.5$ & $n=1$ & $n=5$ \\
\hline \multirow[t]{7}{*}{ UTR } & 20 & 20 & 0.8786 & 0.9715 & 1.0592 & 1.2134 \\
\hline & & 40 & 0.9511 & 1.0852 & 1.1809 & 1.4238 \\
\hline & & 60 & 1.0526 & 1.2188 & 1.3703 & 1.6978 \\
\hline & & 80 & 1.1831 & 1.3767 & 1.6467 & 2.0607 \\
\hline & 40 & 20 & 0.8860 & 1.0299 & 1.1512 & 1.2958 \\
\hline & & 40 & 0.9858 & 1.1614 & 1.3063 & 1.4651 \\
\hline & & 60 & 1.1084 & 1.3236 & 1.4979 & 1.6586 \\
\hline
\end{tabular}

\begin{tabular}{lllllll}
\hline \hline \multirow{3}{*}{ NLTR } & & 80 & 1.2574 & 1.5253 & 1.7349 & 2.2486 \\
& 20 & 0.8428 & 0.8428 & 1.0010 & 1.1236 \\
& & 40 & 0.8746 & 0.9636 & 1.0505 & 1.2072 \\
& & 60 & 0.9074 & 1.0130 & 1.1037 & 1.3011 \\
& 80 & 0.9420 & 1.0655 & 1.1610 & 1.4081 \\
& 40 & 20 & 0.8566 & 0.9682 & 1.0787 & 1.2191 \\
& 40 & 0.8829 & 1.0207 & 1.1406 & 1.2906 \\
& & 60 & 1.3377 & 1.0772 & 1.2073 & 1.3696 \\
& & 80 & 0.9725 & 1.1384 & 1.2795 & 1.4527 \\
\hline \hline
\end{tabular}
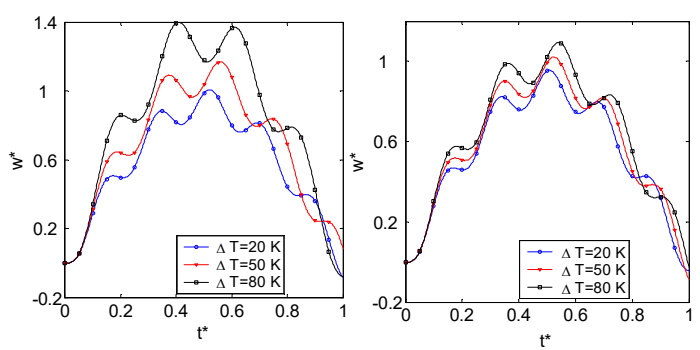

(a) UTR

(b) NLTR

Figure 4. Time histories for mid-span deflection for various values of temperature rise $(n=0.5, V \alpha=0.1, v=30 \mathrm{~m} / \mathrm{s})$.
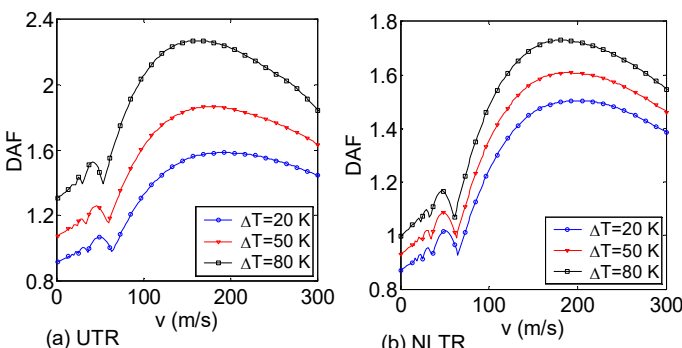

Figure 5. Relation between DAF and moving speed for various values of temperature rise $(n=0.5, V \alpha=0.1)$.
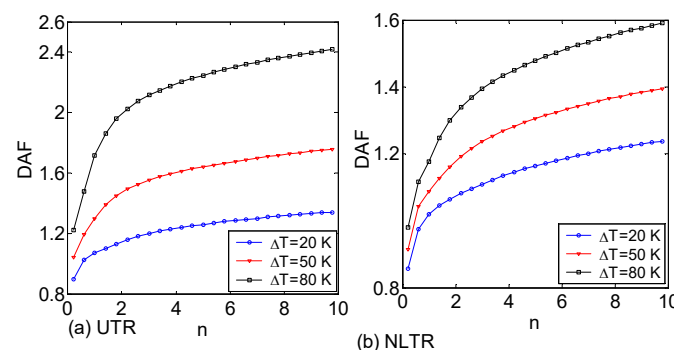

Figure 6. The relation between DAF and grading index $\mathrm{n}$ for various values of temperature rise $(\mathrm{V} \alpha=0.1, \mathrm{v}=30 \mathrm{~m} / \mathrm{s})$

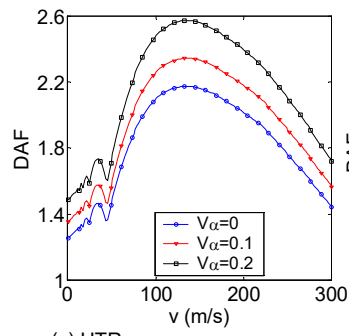

(a) UTR

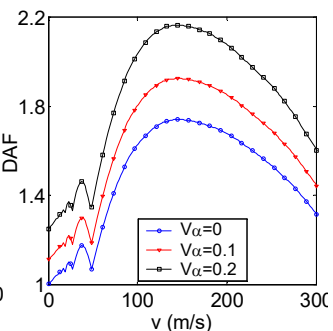

(b) NLTR
Figure 7. Relation between DAF and moving speed for different porosity volume fractions $(n=3, T=50 \mathrm{~K})$. 


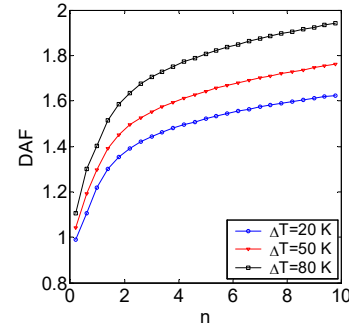

(a) UTR

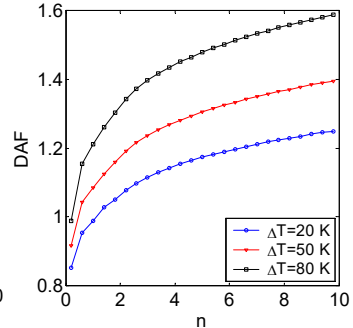

(b) NLTR

Figure 8 . The relation between DAF and grading index $n$ for different porosity volume fractions ( $T=50 \mathrm{~K}, v=30 \mathrm{~m} / \mathrm{s}$ )

The effect of the temperature rise on the dynamic response of the beam is further illustrated in Figs. 4-6. The mid-span dynamic deflection, as seen from Fig. 4, is increased by the increase of the temperature rise for most the traveling time of the moving load. In addition, the temperature rise alters the time at which the deflection attains a maximum value, but it hardly affects the way the beam vibrates. The curves of the relation between the DAF and the moving speed of the FGM porous beam, depicted in Fig. 5 for various values of the temperature rise, are similar to that of the FGM beam without the temperature and porosity effect [6], [12], and the DAF experiences a period of repeated increase and decrease by the increase of the moving speed, it then monotonously increases to a maximum value. Irrespective of the moving speed and the type of temperature distribution, the DAF increases by the increase of the temperature rise. The increase of the DAF by the temperature rise is also seen from Fig. 6, where the relation between the DAF and the index $n$ is displayed for various values of the temperature rise. It can be observable again from Figs. 5 and 6 that the DAF obtained in the NLTR is considerably lower than that obtained in UTR, regardless of the moving speed and the grading index $n$.

Fig. 7 shows the relation between the DAF and the moving load speed for different porosity volume fractions $\mathrm{V}_{\alpha}$ and for a grading index $n=3$, a temperature rise $T=50 \mathrm{~K}$. The relation between the DAF and the grading index $n$ for different porosity volume fractions and for $T=50 \mathrm{~K}, v=30$ $\mathrm{m} / \mathrm{s}$ is depicted in Fig. 8. The figures show a significant influence of the porosity volume fraction and the temperature rise on the DAF of the beam. The DAF, as can be seen clearly from Fig. 7, increases with increasing the porosity volume fraction, regardless of the temperature type. The effect of the temperature rise is similar to that of

the porosity volume fraction, and the DAF is also increased when increasing the temperature rise, irrespective of the grading index $n$. Among the two types of the temperature considered herein, the uniform temperature rise has more significant influence on the DAF than the nonlinear temperature rise does. At the same increment of the porosity or temperature rise, the DAF increases more significantly by the uniform temperature rise than it does by the nonlinear temperature rise.

TABLE 4

DAF FOR DIFFERENT VALUES OF POROSITY VOLUME FRACTION AND GRADING INDEX $n(\mathrm{~T}=50 \mathrm{~K})$

\begin{tabular}{ccccccc}
\hline \hline $\begin{array}{c}\text { Tem } \\
\text { perat } \\
\text { ure }\end{array}$ & $v$ & $V_{\alpha}$ & $n=0.2$ & $n=0.5$ & $n=1$ & $n=5$ \\
\hline UTR & 20 & 0 & 0.9496 & 1.0759 & 1.1813 & 1.4368 \\
& & 0.1 & 0.9959 & 1.1492 & 1.2592 & 1.5518 \\
& & 0.2 & 1.0727 & 1.2406 & 1.3687 & 1.7076 \\
& 40 & 0 & 1.0028 & 1.1682 & 1.3013 & 1.4408 \\
& & 0.1 & 1.0446 & 1.2390 & 1.3979 & 1.5605 \\
& & 0.2 & 1.0937 & 1.3281 & 1.5227 & 1.7141 \\
NLT & & & & & & \\
R & 20 & 0 & 0.8195 & 0.9090 & 0.9800 & 1.1275 \\
& & 0.1 & 0.8908 & 0.9879 & 1.0770 & 1.2529 \\
& & 0.2 & 0.9754 & 1.0852 & 1.1999 & 1.2830 \\
& 40 & 0 & 0.8469 & 0.9677 & 1.0696 & 1.2026 \\
& & 0.1 & 0.9015 & 1.0485 & 1.1734 & 1.3296 \\
& & 0.2 & 0.9951 & 1.1479 & 1.1479 & 1.4921 \\
\hline \hline & & & & & &
\end{tabular}

In Table 4 , the DAF of the beam under a temperature rise $T=50 \mathrm{~K}$, carrying a moving load with $v=20 \mathrm{~m} / \mathrm{s}$ and $40 \mathrm{~m} / \mathrm{s}$, is listed for various values of the porosity volume fraction $V \alpha$ and the grading index $n$. The Table shows an increase in the DAF by the increase of the porosity volume fraction $V \alpha$, regardless of the index $n$ and the moving speed. The effect of the porosity volume fraction is also clearly seen from Figs. 7 and 8, where the relations between the DAF with moving speed $v$, and the relation of the DAF with index $n$ are depicted for different porosity volume fractions and for $T=50 \mathrm{~K}$. As seen from the figures, the DAF increases by the increase of the $V \alpha$, regardless of the moving speed and the index $n$. The increase of the DAF by the porosity volume fraction may be resulted from the lower rigidities of the beam with a higher volume fraction.

\section{CONCLUSION}

The effect of temperature and porosities on the dynamic response of FGM beams carrying a moving load has been investigated in this paper. The material properties are assumed to be 
temperature dependent and they are graded in the thickness direction by a power-law distribution. A modified rule of mixture, taking the effect of porosities into account, is adopted to evaluate the effective properties of the beam. Two types of temperature distribution, namely the uniform and nonlinear temperature rises obtained from Fourier equation are considered. Equations of motion based on Euler-Bernoulli beam theory are derived and they are solved by a simple finite element formulation in combination with the Newmark method. A parametric study has been carried out to highlight the effect of the temperature rise and the porosity volume fraction on the dynamic response of the beam. Numerical results show that the DAF is increased by the increase of the temperature rise and the porosity volume fraction. Among the two types of the temperature distribution considered in the present work, the uniform temperature rise affects the dynamic response more strongly. The result of this paper reveals that the temperature and the porosities play an important role on the dynamic behaviour and they must be taken into consideration in analysis of FGM beams traversed by moving loads.

\section{REFERENCES}

[1] A. Chakraborty, S. Gopalakrishnan, and J.N. Reddy, "A new beam finite element for the analysis of functionally graded materials", Int. J. Mech. Sci., 45(3), 519-539, 2003.

[2] R. Kadoli, K. Akhtar, and N. Ganesan, "Static analysis of functionally graded beams using higher order shear deformation theory", Appl. Math. Model, 32(12), 2509$2525,2008$.

[3] X.-F. Li, "A unified approach for analyzing static and dynamic behaviours of functionally graded Timoshenko and Euler-Bernoulli beams", J. Sound Vib., 318(4-5), 12101229, 2008.

[4] A.E.Alshorbagy, M.A. Eltaher, and Mahmoud, "Free vibration chatacteristics of a functionally graded beam by finite element method", Appl. Math. Model., 35(1), 412425, 2011.

[5] A. Shahba, R. Attarnejad, M.T. Marvi, and S. Hajilar, "Free vibration and stability analysis of axially functionally graded tapered Timoshenko beams with classical and nonclassical boundary conditions", Compos. Part B-Eng., 42(4), 801-808, 2011.

[6] D.K. Nguyen, "Large displacement response of tapered cantilever beams made of axially functionally graded material", Compos. Part B-Eng., 55 298-305, 2013.

[7] D.K. Nguyen, "Large displacement behaviour of tapered cantilever EulerBernoulli beams made of functionally graded material" Appl. Math. Comput. 237, 340355, 2014.

[8] D.K. Nguyen and B.S. Gan, "Large deflections of tapered functionally graded beams subjected to end forces", Appl. Math. Model., 38(11-12), 3054-3066, 2014.

[9] M. Meradjah, A. Kaci, M.S.A. Houari, A. Tounsi, and S.R. Mahmoud, "A new higher order shear and normal deformation theory for functionally graded beams", Steel Compos. Struct., 18(3), 793-809, 2015.

[10] B. Sallai, L. Hadji, T.H. Daouadji, and E.A. Adda Bedia, "Analytical solution for bending analysis of functionally graded beam”, Steel Compos. Struct., 19(4), 829-841, 2015.

[11] R. Bennai, H.A. Atmane, and A. Tounsi, "A new higherorder shear and normal deformation theory for functionally graded sandwich beams", Steel Compos. Struct., 19(3), 521$546,2015$.

[12] M. Şimşek and T. Kocatürk, "Free and forced vibration of a functionally graded beam subjected to a concentrated moving harmonic load", Compos. Struct., 90(4), 465-473, 2009.

[13] M. Şimşek "Vibration analysis of a functionally graded beam under a moving mass by using different beam theories", Compos. Struct., 92(4), 904-917, 2010.

[14] M. Şimşek, "Non-linear vibration analysis of a functionally graded Timoshenko beam under action of a moving harmonic load", Compos. Struct., 92(10), 25322546, 2010.

[15] S.M.R.Khalili,A.A. Jafari, and S.A. Eftekhari, "A mixed Ritz-DQ method for forced vibration of functionally graded beams carrying moving loads", Compos. Struct., 92(10), 2497-2511, 2010.

[16] K. Rajabi,M.H. Kargarnovin, and M. Gharini, "Dynamic analysis of a functionally graded simply supported EulerBernoulli beam to a moving oscilator", Acta Mechanica., 224(2), 425-446. 16, 2013.

[17] D.K. Nguyen, B.S.Gan, and T.H. Le "Dynamic response of non-uniform functionally graded beams subjected to a variable speed moving load", J. Comput. Sci. Tech. (JSME), 7(1), 12-27, 2013.

[18] B.S.Gan, T.H.Trinh, T.H.Le, and D.K.Nguyen, "Dynamic response of nonuniform Timoshenko beams made of axially FGM subjected to multiple moving point loads", Struct. Eng. Mech., 53(5), 981-995.15, 2015.

[19] Y.W. Kim, "Temperature dependent vibration analysis of functionally graded rectangular plates", J. Sound Vib, 284(1-3), 531-549, 2005.

[20] S.C. Pradhan, and T. Murmu, "Thermo-mechanical vibration of FGM sandwich beam under variable elastic foundations using differential quadrature method", J. Sound Vib, 321(1-2), 342-362, 2009.

[21] A. Mahi, E.A. Adda Bedia, A. Tounsi, and I. Mechab, “An analytical method for temperature-dependent free vibration analysis of functionally graded beams with general boundary conditions", Compos. Struct., 92(8), 1877-1887, 2010.

[22] N. Wattanasakulpong, B. Gangadhara Prusty, and D.W. Kelly, "Thermal buckling and elastic vibration of thirdorder shear deformable functionally graded beams", Int. J.Mech. Sci., 53(9), 734-743, 2011.

[23] N. Wattanasakulpong and A. Chaikittiratana, "Flexural vibration of imperfect functionally graded beams based on Timoshenko beam theory: Chebyshev collocation method", Meccanica, 50(5), 1331-1342. 1, 2015.

[24] H.A. Atmane,A. Tounsi,F. Bernard, and S.R. Mahmoud, "A computational shear displacement model for vibrational analysis of functionally graded beams with porosities", Steel Compos. Struct., 19(2), 369-385, 2015.

[25] D. Chen, J. Yang, and S. Kitipornchai, "Elastic buckling and static bending of shear deformable functionally graded porous beam", Compos. Struct., 133, 54-61, 2015.

[26] F. Ebrahimi, F. Ghasemi, and E. Salari, "Investigating thermal effects on vibration behavior of temperaturedependent compositionally graded Euler beams with porosities", Meccanica, DOI 10.1007/s11012-015-0208-y, 2015. 
[27] Y.S.Touloukian, Thermophysical Properties of High Temperature Solid Materials, New York, Macmillan, 1967.

[28] M. Géradin and D. Rixen, Mechanical Vibrations. Theory and application to structural dynamics, 2nd edition, John Willey \& Sons, Chichester, 1997.

Bui Van Tuyen received the M.S. degree in mechanical engineering from University of Transport and Communication. $\mathrm{He}$ is a lecturer at ThuyLoi University, and he is currently working for a $\mathrm{Ph} . \mathrm{D}$ degree at
Institute of Mechanics, Vietnam Academy of Science and Technology. His research topics include the structural design and dynamic finite element analysis of functionally graded structures.

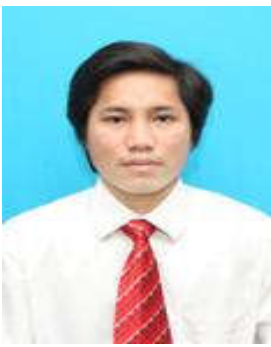

\section{Ảnh hưởng của nhiệt độ và lỗ rỗng vi mô tới đáp ứng động lực học của dầm FMG chịu lực di động}

Bùi Văn Tuyển

Tóm tắt - Bài báo nghiên cứu ảnh hưởng của nhiệt độ và lỗ rỗng vi mô tới đáp ứng động lực học của dầm làm từ vật liệu có cơ tính biến thiên (FGM) chịu lực di động. Trường nhiệt độ phân bố đều và phân bố phi tuyến theo chiều cao dầm được quan tâm nghiên cứu. Tính chất vật liệu được giả định phụ thuộc vào nhiệt độ và thay đổi theo chiều cao dầm theo quy luật hàm số mũ. Luật phối trộn cải biên có tính tới ảnh hưởng của lỗ rỗng vi mô được dùng để đánh giá các tính chất hiệu dụng. Phương trình chuyển động được thiết lập trền cơ sở lý thuyết dầm Euler-Bernoulli và được giải bằng phương pháp phần tử hữu hạn kết hợp với thuật toán Newmark. Kết quả số chỉ ra rằng hệ số động lực học tăng khi nhiệt độ và tỷ lệ thể tích lỗ rỗng tăng. Sự tăng của hệ số động lực học bởi trường nhiệt độ đồng nhất mạnh hơn, đặc biệt với dầm có tham số vật liệu cao hơn.

Tù khóa - Vật liệu có cơ tính biến thiên, lỗ rỗng vi mô, tính chất phụ thuộc nhiệt độ, đáp ứng động lực học, dầm Euler-Bernoulli. 